\title{
WITANOWSKI'S DISCOVERY \\ - AND HOW ITS EARLY MISINTERPRETATION AND SUBSEQUENT NEGLECT CONTINUE TO IMPEDE SCIENTIFIC PROGRESS AND INSIGHT
}

JAN SCHLAUER • Zwischenstr. 11 • D-60594 Frankfurt/Main•Germany • jan@carnivorousplants.org

Keywords: Drosera, phytochemistry, naphthoquinones, chemotaxonomy.

Abstract: W.R. Witanowski isolated and characterized the naphthoquinone ramentaceone from Drosera rotundifolia in 1934 and named the compound droserone. This constitutes the first publication that described the correct detailed structure of the main naphthoquinone in a sundew species, the first publication that identified ramentaceone as a natural product, and the first publication to introduce the name droserone for this naphthoquinone. Nevertheless, none of these facts is reflected appropriately in the literature until now. This prompts a reappraisal.

Introduction and some general remarks

The history of science is popularly portrayed as a series of success: cognitive improvements linked to each other by logic, and experience (frequently mistaken for knowledge) is stated to be the basis for "educated guesses", the hypotheses that - in the case of natural sciences - need to be tested (ideally, confirmed) by (ideally, ingenious) experiments. A somewhat less positivistic view has science as the laborious process of correcting mistakes, the discovery and elimination of previous failures, some of which are surprisingly influential in hindsight. While either perspective has a certain justification, both underestimate the influence of the interested parties, humans with intentions, opinions, and bias.

It is the aim of this note to correct a few mistakes that occurred early in the exploration of the chemical constituents of sundews, to rehabilitate an important researcher in this field and to explain how this all affects our current understanding of the matter.

Witold Rawita-Witanowski (1899-1945), biochemist, neurophysiologist, and pharmacologist, was the last Dean of the Faculty of Pharmacy at the University of Warsaw in the pre-war time (Witanowska \& Wroczyński 2018), and his most important discovery in the context of carnivorous plants became a victim of its historical circumstances (in which German colleagues played an unfortunate role; being German, the present author hopes this text will help to set some of this injustice straight) just like the person became a victim of the murderous German regime after the Warsaw Uprising.

The (apparent) state of play until 2020

The acetogenic naphthoquinones, plumbagin (5-hydroxy-2-methyl-1,4-naphthoquinone, 2-methyljuglone, P in this paper, cf. scheme 1) and ramentaceone (5-hydroxy-7-methyl-1,4-naphthoquinone, 7-methyljuglone, $\mathrm{M}$ in this paper), are important chemotaxonomic markers in sundews (Drosera L., Culham \& Gornall 1994, Schlauer et al. 2017, 2018) because most species contain only one (main) isomer or no naphthoquinone at all; both isomers together (at equal amounts) are almost exclusively found in hybrids between quinone-heterogenous species (Schlauer \& Fleischmann 2016). The distribution of the isomers in the genus (Zenk et al. 1969) has demonstrated their chemotaxonomic significance. 
Scheme 1:

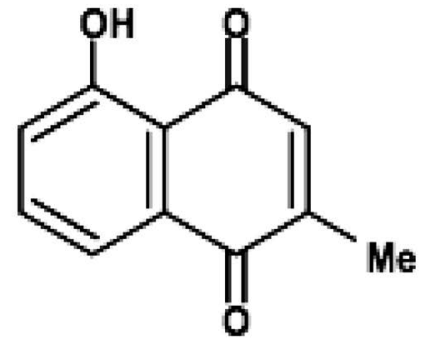

Plumbagin (P)

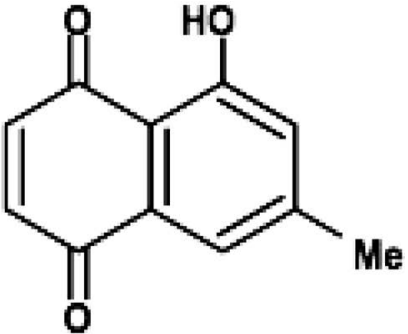

Ramentaceone (M)

According to experts in the field (Thomson 1957), within Droseraceae P was first isolated from Drosera rotundifolia (Witanowski 1934, Dieterle 1935), D. binata (Dieterle 1935), D. peltata (Asano \& Hase 1943), and D. intermedia (Denoël 1949).

M was apparently (Thomson 1971) discovered in sundews much later, after it was first identified and distinguished from P in Diospyros (Cooke et al. 1952), in Drosera "ramentacea" (Paris \& Delaveau 1959; later identified as D. madagascariensis), D. intermedia (Bendz \& Lindberg 1968), D. aliciae and D. capensis (Zenk et al. 1969). As evident from the annotation, already the early history was heavily compromised by wrong species identification, but as we shall see swiftly, also the chemical structures assigned to the isolated compounds were more guesswork guided by misleading expectations than evidence-based elucidation.

The true story or what went wrong, what is wrong and why

In his ground-breaking (but unfortunately, fundamentally and frequently misunderstood) work, Witanowski (1934) demonstrated by an unambiguous degradation reaction that the compound he isolated from (correctly identified) D. rotundifolia and that he called droserone was a naphthoquinone with a methyl group in the phenolic ring (i.e., not in the quinoid ring!). In contrast, the isomer $\mathrm{P}$ has the methyl group in the quinoid ring.

In other words, Witanowski (1934) was the first to determine the correct constitution of $\mathrm{M}$ as a natural product, and the first trivial name of the compound was droserone. The fact that Dieterle (1935) attributed the (wrong) P structure to the quinone from the same species only a few months later was most probably caused by his simultaneous investigation of another species $(D$. binata, that really contains $\mathrm{P}$ ) and the (wrong) assumption that one genus could only contain one characteristic quinone. For various reasons, Dieterle's (wrong) and not Witanowski's (correct) conclusion on the structure of the main naphthoquinone from D. rotundifolia prevailed and persisted. Also Witanowski's name droserone was (again, only a few months later!) used for a different compound, viz. 3-hydroxyplumbagin (3,5-dihydroxy-2-methyl-1,4-naphthoquinone, Macbeth et al. 1935, first detected in $D$. whittakeri by Rennie 1887), and this later homonym persists in the literature.

Only the entirely wrong interpretation and the subsequent neglect (essentially caused and initiated by Dieterle 1935) of Witanowski's (1934) results made later investigators think they (Cooke et al. 1952) had determined the structure of $M$ for the first time or they (Paris \& Delaveau 1959) had the obligation to give it a new trivial name, or even made them (Macbeth et al. 1935) use Witanowski's original name droserone for a different compound that is ironically again derived from the opposite isomer P. Witanowski was thus the researcher who in reality made the first discoveries for which not less than three different, subsequent publications claimed priority, all of which based essentially on the erroneous claims in a fourth subsequent publication! 
Although it was indicated from the beginning (Bendz \& Lindberg 1968) that M was only a trace constituent of $D$. intermedia (the main isomer in this species being $\mathrm{P}$ ), some authors (Zenk et al. 1969 ) only mentioned the minor constituent, which resulted in considerable confusion in the subsequent literature (Egan \& van der Kooy 2013).

The proposed and the actual structures and names with the respective references are summarized in the following table.

\begin{tabular}{|l|l|l|l|}
\hline \multicolumn{1}{|c|}{ Source species } & \multicolumn{1}{|c|}{ Reference } & \multicolumn{1}{|c|}{$\begin{array}{c}\text { Name used for } \\
\text { Quinone in } \\
\text { Reference }\end{array}$} & \multicolumn{1}{|c|}{$\begin{array}{c}\text { Isomer } \\
\text { actually found }\end{array}$} \\
\hline Drosera rotundifolia & Witanowski 1934 & Droserone & M \\
\hline D. whittakeri & Macbeth et al. 1935 & Droserone & 3-Hydroxy-P \\
\hline D. rotundifolia & Dieterle 1935 & Plumbagin & M \\
\hline D. binata & Dieterle 1935 & Plumbagin & $\mathrm{P}$ \\
\hline D. peltata & Asano \& Hase 1943 & Plumbagin & $\mathrm{P}$ \\
\hline D. intermedia & Denoël 1949 & Plumbagin & $\mathrm{P}$ \\
\hline $\begin{array}{l}\text { D. "ramentacea"; } \\
\text { later identified as } \\
\text { D. } \text { madagascariensis }\end{array}$ & Paris \& Delaveau 1959 & Ramentaceone & $\mathrm{M}$ \\
\hline $\begin{array}{l}\text { D. } \text { intermedia } \\
\text { D. aliciae, D. capensis } \\
\text { and several other spp. }\end{array}$ & Zenk et al. 1969 & 7-Methyljuglone & $\mathrm{M}$ \\
\hline $\begin{array}{l}\text { D. binata, D. whittakeri } \\
\text { and several other spp. }\end{array}$ & Zenk et al. 1969 & Plumbagin & $\mathrm{P}$ \\
\hline
\end{tabular}

Even more recently, in a fairly successful attempt to revise the structure and biosynthetic origin of an indanone derivative of $\mathrm{P}$ from Triphyophyllum peltatum (Ishii et al. 2019), Witanowski was credited for having isolated the $\mathrm{P}$ derivative droserone (use of the name in the sense of Macbeth et al. 1935, not Witanowski 1934) from D. rotundifolia. As the (main) isomer found in D. rotundifolia is $\mathrm{M}$ and not $\mathrm{P}$, this reference led the author of the present note to study the original source, which resulted in the discoveries outlined above.

\section{Conclusions}

The lesson to be learned from this story is simply what should be general practice in science, viz. to read, understand, and appreciate what colleagues (irrespective of the respective persons' social status or provenance) have achieved in one's field. This includes proper citation. As a practical consequence, we should recognize Witanowski (1934) as the first researcher who correctly identified a specific naphthoquinone (M) from a carnivorous plant (and thus, the first who isolated and identified M from a plant whatsoever). His designation "droserone" (for M) did unfortunately never gain general acceptance among chemists, and as it is now the "standard" trivial name for a different compound (Macbeth et al. 1935), its original meaning should rather not be restored because this would cause more confusion than clarity. Instead, the later (Paris \& Delaveau 1959) proposed name "ramentaceone" (although it was originally derived from a confused source species) is sufficiently descriptive, widely used and unambiguous to replace Witanowski’s "droserone". 
Acknowledgements: When this note was written, the scientific community was severely affected (and not so much infected) by a coronavirus pandemic and particularly so by the administrative measures taken to prevent its further spread. This caused some hardship in obtaining essential literature, and for this reason I am particularly indebted to my colleagues who helped to gather what was required for this text. I would especially like to express my sincere gratitude to Jaromir Budzianowski, Poznań, Heiko Rischer, Helsinki, Lubomir Adamec, Třeboň, and Maciej Strzemski, Lublin.

\section{References}

Asano, M., and Hase, J. 1943. Hydroxyquinones X. Pigment of Drosera peltata. J. Pharm. Soc. Japan (Yakugaku Zasshi) 63: 410-411.

Bendz, G., and Lindberg, G. 1968. Naphthoquinones and anthocyanins from two Drosera species. Acta Chem. Scand. 22: 2722-2723.

Cooke, R.G., Dowd, H., and Webb, L.J. 1952. Naphthoquinones from Diospyros hebecarpa. Nature (Lond.) 169: 974.

Culham, A., and Gornall, R.J. 1994. The taxonomic significance of naphthoquinones in the Droseraceae. Biochem. Syst. Ecol. 22: 507-515.

Denoël, A. 1949. Determination de l'activité des Droseras indigénes et de leurs teintures. J. Pharm., Belg. 4(1-2): 3-19.

Dieter1e, H. 1935. Die Inhaltsstoffe von Drosera rotundifolia. Arch. Pharm., Berl. 273: 235-236.

Egan, P., and van der Kooy, F. 2013. Phytochemistry of the carnivorous sundew genus Drosera (Droseraceae) - Future perspectives and ethnopharmacological relevance. Chemistry \& Biodiversity 10: $1774-1790$.

Ishii, Y., Ota, M., Kamo, S., Tomoshige, S., Tsubaki, K., and Kuramochi, K. 2019. Synthesis and structural revision of an indanone isolated from Triphyophyllum peltatum. Tetrahedron Letters 61 (7): 151494.

Macbeth, A.K., Price, J.R., and Winzor, F.L. 1935. The colouring matters of Drosera whittakeri. Part I. The absorption spectra und colour reactions of hydroxy-naphthaquinones. J. Chem. Soc. 1935: 325-333.

Paris, R., and Delaveau, P. 1959. Recherches sur les Droséras. Ann. Pharm. France 17: 585-592.

Rennie, E.H. 1887. The colouring matter of Drosera Whittakeri. J. Chem. Soc. Lond. 51: 371-377.

Schlauer, J., and Fleischmann, A. 2016. Chemical evidence for hybridity in Drosera (Droseraceae). Biochem. Syst. Ecol. 66: 33-36.

Schlauer, J., Hartmeyer, S.R.H., and Hartmeyer, I. 2017. Unexpected discovery of 7-methyljuglone (ramentaceone) in several Australian sundews. Carniv. P1. Newslett. 46: 20-22.

Schlauer, J., Hartmeyer, S.R.H., Hartmeyer, I., Hennern, H., and Hennern, A. 2018. Sundew chemistry and emergence updates. Carniv. Pl. Newslett. 47: 10-17.

Thomson, R.H. 1957. Naturally Occurring Quinones. Butterworths.

Thomson, R.H. 1971. Naturally Occurring Quinones, 2nd ed. Academic Press.

Witanowska, J., and Wroczyński, P. 2018. Echoes from the past: Professor Witold Rawita-Witanowski, 1899-1945, Biochemist, Neurophysiologist, and Pharmacologist, First Editor of Acta Poloniae Pharmaceutica. Acta Poloniae Pharmaceutica - Drug Research 75(2): 275-280.

Witanowski, W.R. 1934. Badania nad składem chemicznym rosiczki okrạgłolistnej Drosera rundifolia L. Wiadomosći Farmaceutyczne 61(29): 420-422 \& 61(30): 432-433.

Zenk, M.H., Fürbringer, M. and Steglich, W. 1969. Occurrence and distribution of 7-metyljuglone and plumbagin in the Droseraceae. Phytochemistry 8: 2199-2200. 